\title{
Inverse modeling of emissions for local photooxidant pollution: Testing a new methodology with kriging constraints
}

\author{
I. Pison ${ }^{1}$, L. Menut ${ }^{2}$, and N. Blond ${ }^{3}$ \\ ${ }^{1}$ LISA, Université Paris 7, Paris 12, CNRS, UMR7583, Créteil, France \\ ${ }^{2}$ LMD/IPSL, UMR8539, Ecole Polytechnique, Palaiseau, France \\ ${ }^{3}$ LISA, Université Paris 7, Paris 12, CNRS, UMR7583, Créteil, France
}

Received: 13 May 2005 - Revised: 24 April 2006 - Accepted: 12 May 2006 - Published: 3 July 2006

\begin{abstract}
A new methodology for the inversion of anthropogenic emissions at a local scale is tested. The inversion constraints are provided by a kriging technique used in air quality forecast in the Paris area, which computes an analyzed concentration field from network measurements and the first-guess simulation of a CTM. The inverse developed here is based on the CHIMERE model and its adjoint to perform 4-D integration. The methodology is validated on synthetic cases inverting $\mathrm{NO}_{\mathrm{x}}$ emission fluxes. It is shown that the information provided by the analyzed concentrations is sufficient to reach a mathematically acceptable solution to the optimization, even when little information is available in the measurements. As compared to the use of measurements alone or of measurements and a background matrix, the use of kriging leads to a more homogeneous distribution of the corrections, both in space and time. Moreover, it is then possible to double the accuracy of the inversion by performing two kriging-optimization cycles. Nevertheless, kriging analysis cannot compensate for a very important lack of information in the measurements.
\end{abstract}

Keywords. Atmospheric composition and structure (Pollution-urban and regional; Troposphere-composition and chemistry; General or miscellaneous)

\section{Introduction}

Atmospheric pollution is the result of various interacting processes: emissions, chemistry, transport, mixing and deposition of gaseous species. At a local scale, i.e. areas of $\sim 100 \times 100 \mathrm{~km}$ over time periods of a day or a week, chemistry-transport models are powerful tools to study and forecast air pollution. Yet the accuracy of simulated concentrations largely depends on the quality of the input emis-

Correspondence to: L. Menut

(menut@1md.polytechnique.fr) sion inventories (Menut, 2003). These inventories are generally built through "bottom-up" methodologies that give the annual spatialization of total emitted masses for species or families followed by a time distribution derived from typical profiles for the month, the day of the week (week/weekend/holiday for example) and the hour (see http://www. emep.int and http://webdab.emep.int). The emitted masses of pollutants are usually estimated using some discrete flux measurements and activity sector statistics. These data are heterogeneous and necessarily incomplete. Moreover, because emissions have a large spatial and time variability, the updating of emitted masses is quite difficult (Kühlwein and Friedrich, 2000). As a result, the inventories of hourly emission fluxes often have huge uncertainties and are not adapted to particular events. They are therefore a major source of uncertainty on simulated concentrations. Since it would be difficult today to improve their building methodologies, there remains the possibility of adding information to existing inventories. The optimization of emissions uses the information available in measurements to retrieve the inventory that gives the best agreement between simulated and measured concentrations.

Inverse modeling consists of minimizing the difference between observations and model outputs in order to better estimate model parameters which are allowed to be modified. These methods are based on algorithms derived from the field of data assimilation (Talagrand and Courtier, 1987; Talagrand, 1997) and have only been recently applied to various problems in the atmosphere (Enting, 2002) and particularly to the problem of the inversion of emissions with concentration measurements (Reeves et al., 2004).

Most of the studies available today deal with global or continental scales which means species with long lifetimes, such as methane (Hein et al., 1997; Houweling et al., 1999; Wang and Bentley, 2002), carbon dioxide (Bousquet et al., 1999; Kaminski and Heimann, 2001; Rödenbeck et al., 2003; Gurney et al., 2005), CFCs (Hartley and Prinn, 1993; Mahowald

Published by Copernicus GmbH on behalf of the European Geosciences Union. 
et al., 1997) and carbon monoxide (Bergamaschi et al., 2000; Pétron et al., 2002, 2004; Wang et al., 2004; Müller and Stavrakou, 2005) and, at a continental scale, nitrogen oxides $\left(\mathrm{NO}_{\mathrm{x}}\right)$ (Wang et al., 2004; Konovalov et al., 2005). At a local scale, only five studies on boundary layer pollution over large urbanized areas are available. Three of them are based on the 1992 measurement campaign in the Atlanta area and deal with the inversion of isoprene (Chang et al., 1996), carbon monoxide (Chang et al., 1997) and ozone precursors such as VOCs and $\mathrm{NO}_{\mathrm{x}}$ (Mendoza-Dominguez and Russell, 2001). Mulholland and Seinfeld (1995) studied carbon monoxide in the Los Angeles area. Quélo et al. (2005) inverted $\mathrm{NO}_{\mathrm{x}}$ emissions in Lille (France).

The problems that arise differ according to the spatiotemporal scale (Enting, 2002). At a large scale, transport is the main process linking emissions to concentrations. Therefore, in all these studies, concentration measurements of the studied species are used for constraining the inversion of emissions of the same species. At a local scale, chemical processes play a significant part in the resulting concentrations. The use of ozone measurements to invert the emissions of precursors, such as VOCs and $\mathrm{NO}_{\mathrm{x}}$, has been proved to yield realistic results, provided that there are a lot of constraints, as is the case during a measurement campaign, for example, in Mendoza-Dominguez and Russell (2001) and Quélo et al. (2005). Nevertheless, when the measured species are either the same as the inverted species (Mulholland and Seinfeld, 1995; Chang et al., 1996, 1997) or are directly linked to the emissions (as is the case with $\mathrm{NO}_{\mathrm{x}}$ emissions and $\mathrm{NO}$ or $\mathrm{NO}_{2}$ measurements in Quélo et al. (2005)), errors due to uncertainties in the chemical processes are reduced.

The features of emissions themselves are very different at large and small scales. At a large scale, emissions are generally assumed to be homogeneous on a large area (typically a continent) (Bousquet et al., 1999; Heimann and Kaminski, 1999) and two approaches are usually used, synthesis and mass balance (Enting, 2002). Only Kaminski et al. (2001) studied the impact of sub-grid scale aggregation on $\mathrm{CO}_{2}$ surface fields inversion. Therefore, background error covariances are estimated either through spatial correlation models or with climatological data (Kasibhatla et al., 2000; Daley, 1996). On the contrary, at a local scale, emissions are not a continuous process, neither spatially nor temporally. It is therefore particularly difficult to add a priori information in the emission space. Through lack of information, Mulholland and Seinfeld (1995) used a diagonal background matrix.

The needs of air quality forecasting have led to the development of hybridization techniques between measured and simulated concentrations, such as optimal interpolation or kriging. These operating techniques ensure the retrieving of concentration fields, which takes into account the information provided by both the measurements and the validated structure of the simulated concentration field. The analyzed concentrations are therefore the "best known" state of information in the concentration space. In this study, we test the possibility of using the analyzed concentrations provided by a kriging technique used in air quality forecasting, to constrain the inversion of emissions in a large urbanized area. The developed inverse modeling methodology (Sect. 2.3) uses the adjoint approach that makes it possible to take into account the nonlinear links between emissions and concentrations at a time scale that suits local photooxidant pollution. The inverse model itself is based on the CHIMERE model and its adjoint, described in Sects. 2.1. The kriging technique had been developed previously (Blond et al., 2003; Blond and Vautard, 2004) and is shortly described in Sect. 2.2. As a daily forecasting tool, it uses hourly surface measurements made at the air quality monitoring network of the area and does not need additional observations, such as are provided by measurement campaigns. This ensures the portability of the method to a large set of time periods and urban areas. To evaluate the feasibility and accuracy of this new methodology using kriging constraints, we performed synthetic cases of inversion as described in Sect. 2.4. We have focused on the Paris area because (i) the kriging technique has been developed for and first applied to this urban area in which the fully developed AIRPARIF network measurement is available and (ii) it represents a simple type of large urbanized area with a very dense city in the center of the area (emitting intensely), surrounded by gradually less urbanized (and less emitting) suburbs to rural areas. $\mathrm{NO}_{\mathrm{x}}$ emission fluxes were chosen to be inverted because (i) they are ozone precursors with large uncertainties, particularly in their 24-h time profile (Vautard et al., 2003) and (ii) they are directly linked to NO concentrations which are measured by AIRPARIF and can be analyzed by kriging. Formal test cases have been run to quantify the theoretical accuracy of the inverse code (Sect. 3). Then a series of experiments with realistic synthetic cases, based on a real pollution event, have been performed to assess the advantages and limitations of our methodology (Sect. 4).

\section{The inverse modeling system}

Our inverse modeling system is based on the CHIMERE model and its adjoint. The inversion constraints are obtained through the use of a kriging technique. These tools are first presented in this section, followed by the description of the inverse modeling methodology based on the adjoint approach.

\subsection{CHIMERE and its adjoint}

CHIMERE is a chemistry-transport model (CTM) designed to study pollution within the atmospheric boundary layer (ABL) (Vautard et al., 2001). It has been applied to longterm simulations at local and European scales (Schmidt et al., 2001; Vautard et al., 2001), pollution event studies (Schmidt and Martin, 2003; Beekmann and Derognat, 2003) and processes impact studies (Pison and Menut, 2004). CHIMERE 
is part of the French national air quality forecasting system Prev'air (http://www.prevair.org/en/). It is also involved in the City-Delta European project, dedicated to investigating urban air quality evolution due to urban emission changes (http://aqm.jrc.it/citydelta/). The model is freely available on CHIMERE's website (http://euler.lmd.polytechnique.fr/ chimere/). The adjoint of CHIMERE has been developed and used for sensitivity studies by Menut et al. (2000a) and Menut (2003). A complete description of the adjoint theory and sensitivity use may also be found in Talagrand (1997); Daescu et al. (2003); Sandu et al. (2003).

\subsection{The kriging technique}

In this section, we briefly describe the INK kriging technique which has been previously proposed and applied by Blond et al. (2003) to produce realistic ozone and NO concentration maps using surface ozone measurements and simulated concentration fields. The reader is referred to Blond et al. (2003) for further details about the performance of this kriging technique compared to other mapping techniques.

The aim of kriging is to provide an estimate, called the analysis, $y_{t, h}^{a}(s)$ of the value of a concentration field $y_{t, h}(s)$ at any location $s$, at day $t(t=1, \ldots, T)$, and hour $h(h=1 \ldots, 24)$. A set of $K$ spatially distributed measurement values $y_{t, h}^{o}\left(s_{k}\right)$, where $k=1, \ldots, K$ and $s_{k}$ is the location of the k-th monitoring station, is available, together with a prior estimate of the concentration field $y_{t, h}^{b}(\boldsymbol{s})$, which is often called the first-guess field and corresponds here to concentrations simulated by CHIMERE. In this setting, $y_{t, h}^{a}(s)$ is given by:

$y_{t, h}^{a}(s)=y_{t, h}^{b}(s)+\sum_{k=1}^{K} \lambda_{t, h}^{k}(s)\left(y_{t, h}^{o}\left(s_{k}\right)-y_{t, h}^{b}\left(s_{k}\right)\right)$.

Equation (1) shows that the analyzed field is a correction of the CHIMERE simulation by a linear combination of the innovations $X_{t, h}\left(s_{k}\right)=y_{t, h}^{o}\left(s_{k}\right)-y_{t, h}^{b}\left(s_{k}\right)$. The $\lambda_{t, h}^{k}(s)$ are weighting functions that have to be determined.

Under the assumptions (i) that measured and simulated concentrations are independent variables and (ii) that the concentration to be analyzed is an intrinsically stationary variable, the weighting functions are solutions of the following system:

$$
\left\{\begin{array}{l}
\forall k=1, \ldots, K, \\
\sum_{l=1}^{K} \lambda_{t, h}^{l}(s) \gamma_{t, h}\left(s_{k}, s_{l}\right)-\mu=\gamma_{t, h}\left(s_{k}, s\right) \\
\sum_{l=1}^{K} \lambda_{t, h}^{l}(s)=1,
\end{array}\right.
$$

where $\mu$ is a Lagrangian coefficient for the minimization and $\gamma_{t, h}\left(s_{k}, s_{l}\right)=\frac{1}{2} E\left(X\left(s_{k}\right)-X\left(s_{l}\right)\right)^{2}$ is the semi-variance function $(E($.$) denotes the statistical mean). The semi-$ variance depends on the distance between $s_{k}$ and $s_{l}$, so that $\gamma_{t, h}\left(s_{k}, \boldsymbol{s}_{l}\right)=\gamma_{t, h}\left(\left\|s_{k}-s_{l}\right\|\right)=\gamma_{t, h}(r)$ is the semivariogram function with $r=\left\|s_{k}-s_{l}\right\| . \quad \gamma_{t, h}(r)$ is modeled by building an experimental variogram $\gamma_{t, h}^{\text {exp }}$ with the measured and simulated concentrations available at hour $h$ on day $t$. First, distance classes are built with a length interval $L$ and a tolerance $\tau$. Over each distance classe, the variance $\frac{1}{2} E\left(X_{t, h}\left(s_{k}\right)-X_{t, h}\left(s_{l}\right)\right)^{2}$ is then computed. Thirdly, these variances are plotted versus the mean distance of the class. This experimental variogram gives an estimation of $\gamma_{t, h}\left(s_{k}, s_{l}\right)$ at $\sigma_{t, h}^{o 2}\left(s_{k}\right)$, where $\sigma_{t, h}^{o 2}\left(s_{k}\right)$ is the observation error variance, assumed to be homogeneous and constant in time, e.g. $\sigma_{t, h}^{o 2}\left(s_{k}\right)=\sigma_{h}^{o 2}$. Finally, the experimental variogram is fitted by an exponential model with a nugget effect, where the nugget is ideally equal to $\sigma_{h}^{o 2}$. In practice, $\sigma_{h}^{o 2}$ is the maximum variance over all the measurements available at hour $h$ on day $t$. At last, analysis "variances" $\sigma^{a}(s)$ can also be computed with:

$\sigma^{a 2}(s)=\gamma_{t, h}(s, s)-\sum_{l=1}^{K} \lambda_{t, h}^{l}(s) \gamma_{t, h}\left(s, s_{l}\right)-\mu$.

The INK technique described here is used together with CHIMERE by AIRPARIF, the Paris area air quality network, for mapping daily forecasts (available at http://www.airparif. org). The layout of the measurement network of the Paris area has led to choosing a length interval $L=5 \mathrm{~km}$ and a tolerance $\tau=4 \mathrm{~km}$.

\subsection{The inverse modeling methodology}

\subsubsection{The adjoint approach}

Inverse modeling consists of minimizing the distance between observations, which are classically measurements, and are in our new approach kriging-analyzed values and simulated concentrations. This distance is represented by a cost function $J$, depending on the emission fluxes to be inverted which form the vector $\boldsymbol{e}$. The aim of the optimization is then to minimize $J$ with regard to $\boldsymbol{e}$.

In the adjoint approach, the value of $J$ is computed by the forward model and its gradient with respect to $\boldsymbol{e}, \partial \boldsymbol{J} / \partial \boldsymbol{e}$, is computed by the adjoint in one backward-in-time run. A minimizer then uses the gradient to compute corrected emissions that minimize $J$ and $\partial \boldsymbol{J} / \partial \boldsymbol{e}$. The minimization code used is N1QN3 (Gilbert and Lemaréchal, 1989). It uses a limited memory, quasi-Newton method to solve unconstrained minimization problems. The principle consists of determining a descent direction and a step-size along this direction at each iteration. The direction is computed using an approximation of the Hessian and the gradient of the cost function $\partial \boldsymbol{J} / \partial \boldsymbol{e}$ at the current point. The step-size is obtained by a line-search procedure and must satisfy Wolfe's conditions.

The forward-adjoint simulation cycle is iterated until a minimal distance and the final optimized emissions are obtained. In practice, the iterations stop when the precision given for the stopping criterion is reached. 


\subsubsection{The convergence criteria}

The convergence criteria is a key point in inverse modeling studies. For this study, we mixed several types of convergence criteria, in order to ensure the quality of our results.

First, we use a "numerical" convergence criteria, entirely dependent on the N1QN3 minimizer used. This criterion is the ratio between the current norm of the gradient and its norm at the initial point, i.e. with the first-guess emissions $\mathbf{e}_{\mathbf{b}}$. The convergence is then considered as obtained at the current point when the norm of the gradient has been decreased in the chosen proportion. In order to be more physically consistent with the specific problem of local pollution, we combine this criteria with more physical ones.

The convergence criterion is considered to be reached when (i) the difference between the predicted concentrations from one iteration to the next is less than $10^{-2} \mathrm{ppb}$ and (ii) the adjustments in the emission parameters made by the optimization algorithm from one iteration to the next becomes less than $1 \%$.

Thus, convergence is reached when

$\frac{\left\|g_{k}\right\|}{\left\|g_{b}\right\|}<$ epsg

with $\left\|g_{i}\right\|$ the norm of the gradient at the current point $k$ and at the initial point $b$ and eps $g$ is a specified value. Ideally, the optimization should stop when $\left\|g_{k}\right\| \approx 0$, with

$\left\|g_{k}\right\|=\sqrt{\sum_{n=1}^{\operatorname{dim}}\left(\frac{\partial J}{\partial X_{n}}\right)^{2}} \approx \sqrt{\sum_{n=1}^{\operatorname{dim}}\left(\frac{\Delta J}{\Delta X_{n}}\right)^{2}}$.

The assumption (ii) gives $\forall n, \Delta X_{n} \geq 10^{-2}$, i.e. $\forall n$, $\frac{1}{\Delta X_{n}} \leq 10^{2}$. Moreover, $\forall n, \Delta J=J\left(X_{n}+\Delta X_{n}\right)-J\left(X_{n}\right)=$ $\left.\sum_{i=1}^{N} w_{i}\left(Y_{i}\left(X_{n}+\Delta X_{n}\right)\right)^{2}-Y_{i}\left(X_{n}\right)^{2}\right) \quad$ with $\quad Y_{i}\left(X_{n}\right)=$ $y_{\text {sim }}\left(i, X_{n}\right)-y^{a}\left(i, X_{n}\right), Y_{i}$ being concentrations. Assumption (i) then gives $\left.\forall i, Y_{i}\left(X_{n}+\Delta X_{n}\right)\right)^{2}-Y_{i}\left(X_{n}\right)^{2}<10^{4}$, so that $\forall n, \Delta J \leq 10^{-4} \times \sum_{i=1}^{N} w_{i}$. Finally, we obtain $\left\|g_{k}\right\| \approx 0$ when $\left\|g_{k}\right\| \leq \sqrt{\operatorname{dim}} \times \sum_{i=1}^{N} w_{i} \times 10^{-2}$. For better precision, the inversions have been performed with epsg $=\left\|g_{b}\right\| \times \sqrt{\operatorname{dim}} \times \sum_{i=1}^{N} w_{i} \times 10^{-3}$. Since this rough way of estimating a physically consistent value for epsg might not be totally "mathematically correct", we have then tried and validated it as much as possible on academic cases. Note that this definition of the convergence criterion value is also suited to cases without kriging, for which $\sum_{i=1}^{N} w_{i}$ is reduced to $N$ equal to the number of available measurements instead of the total number of cells.

Finally, a maximal number of iterations authorized for the optimization was also defined so that the computing time remains reasonable, i.e. less than twelve hours on an ordinary PC. Note that the kriging analysis in itself takes less than $5 \mathrm{~min}$ for $24 \mathrm{~h}$ and that an adjoint integration is around four times longer than a forward simulation (which runs in less than 10 min for one day). If the optimization does not converge before one of these numbers is reached, the optimization stops at this point.

\subsubsection{The cost function}

In a classical framework, the cost function is expressed with (Talagrand, 1997):

$$
J(e)=\left(\boldsymbol{e}-\boldsymbol{e}_{b}\right)^{T} \mathbf{B}^{-1}\left(\mathbf{e}-\boldsymbol{e}_{b}\right)+\left(\boldsymbol{y}_{\mathrm{sim}}-\boldsymbol{y}^{o}\right)^{T} \mathbf{R}^{-1}\left(\boldsymbol{y}_{\mathrm{sim}}-\boldsymbol{y}^{o}\right),
$$

where the first term represents the quadratic distance between the first-guess $\boldsymbol{e}_{b}$ and the current $\boldsymbol{e}$ and the second term represents the quadratic distance between the measured $y^{o}$ concentrations and the matching simulated concentrations $\boldsymbol{y}_{\text {sim }}$. The matrices $\mathbf{B}$ and $\mathbf{R}$ contain, respectively, the variances and covariances of the background errors and the observation errors. Variances of the measurements are then the diagonal terms of matrix $\mathbf{R}$. The weight of each difference between measured and simulated concentration is therefore inversely proportional to the reliability of the measurement. Each vector may contain components corresponding to several hours which makes it possible to optimize the emissions of a multi-hour time-window by taking into account their impact on concentrations during a longer period.

In the new methodology tested in this study, the use of kriging analysis to constrain the inversion leads to a cost function in the form of:

$J(\mathbf{e})=\left(\mathbf{y}_{\operatorname{sim}}-\boldsymbol{y}^{a}\right)^{T} \mathbf{R}^{\prime-1}\left(\mathbf{y}_{\operatorname{sim}}-\mathbf{y}^{\mathbf{a}}\right)$,

where $\mathbf{y}^{\mathbf{a}}$ contains the analyzed concentrations matching all the simulated concentrations $\mathbf{y}_{\text {sim }}$ and $\mathbf{R}^{\prime}$ is the matrix of analysis covariances. Since the kriging technique only provides us with the variances of the analyzed concentrations, $\mathbf{R}^{\prime}$ is taken to be diagonal. Moreover, information on $\mathbf{e}_{\mathbf{b}}$ is embedded in the analyzed concentrations, since they depend on the simulated concentration field. Therefore, the penalization term expressed with the $\mathbf{B}$ matrix is not used as such in our cost function. This study tests the practicability and limitations of this formulation of $J$ that avoids the problem of the estimation of $\mathbf{B}$.

\subsection{Synthetic cases for evaluating the new methodology}

Our inverse modeling system and methodology are evaluated using synthetic cases. This synthetic approach is commonly used in data assimilation validation (Elbern and Schmidt, 1999; Cirpka and Kitanidis, 2001).

Figure 1 displays the principle of our synthetic inversion procedure. First, an emission inventory is built and is assumed to be the true emission inventory. A forward simulation is then run to compute the true concentrations. Through a selection of stations, a small number of true concentrations is retrieved to be used as measurements. The true values may be perturbed in order to acknowledge observation and other errors. Otherwise, the generation of measurements by use of 
the model avoids the problem of differences between simulated and measured concentrations which are due to numerical diffusion or to representativity of the measurements with regard to the size of the model cell.

Secondly, the first-guess emission inventory is generated by perturbing the true inventory. The perturbation consists of varying the intensity of the chosen emission fluxes. A forward simulation is run to compute the first-guess concentrations.

The kriging is performed with the measurements and the first-guess concentration field, as described in Sect. 2.2. The analyzed concentrations and their variances are then used, as described in Sect. 2.3, as constraints for the inversion.

The inversion of the first-guess inventory is performed. The resulting optimized emission inventory can then be compared to the true inventory, in order to quantify the accuracy of the inverse modeling methodology. Note that in practice, the optimized emission inventory is actually a correction of the first-guess inventory: the fluxes are rescaled by correction coefficients $\delta_{i}$, so that for each inverted flux $i, e_{i}=\delta_{i} \times e_{i, b}$.

This synthetic procedure focuses on emission fluxes: all other parameters and particularly meteorological parameters are not perturbed to simulate the first-guess. Therefore, a poor estimation of these parameters or of diagnostic variables, such as the boundary layer height, does not interfere with the error on the emission inventory. Future studies will have to test the optimization of emission inventories when taking other influential parameters into account at the same time.

The first part of the evaluation of our modeling system deals with the theoretical accuracy of the inverse code and is performed through very simple formal synthetic cases. Realistic synthetic cases are then used to assess the advantages and limitations of our methodology using kriging constraints, as compared to a classical approach.

\section{Testing the inverse code on formal synthetic cases}

\subsection{Mesh and meteorology}

The domain coincides roughly with the Paris area from 1.3 to $3.3^{\circ} \mathrm{E}$ and from 48.1 to $49.4^{\circ} \mathrm{N}$. The mesh is constituted by $10 \times 10$ cells for 5 vertical levels, thicknesses of which are fixed through time. The first level is $20 \mathrm{~m}$ thick. The top four levels have increasing heights determined so as to include up to $300 \mathrm{~m}$ above the maximum boundary layer height and the cells interfaces heights are, respectively, 20, 65, 200, 630, $2000 \mathrm{~m}$ AGL.

The meteorological conditions represent a "classical" summer weather favorable to high photooxidant pollution episodes: high temperatures, low winds and no clouds are prescribed. Wind and temperature are horizontally uniform. The vertical profile of wind is computed using the value prescribed at the surface $\left(4 \mathrm{~m} \cdot \mathrm{s}^{-1}\right)$ and the logarithmic law in

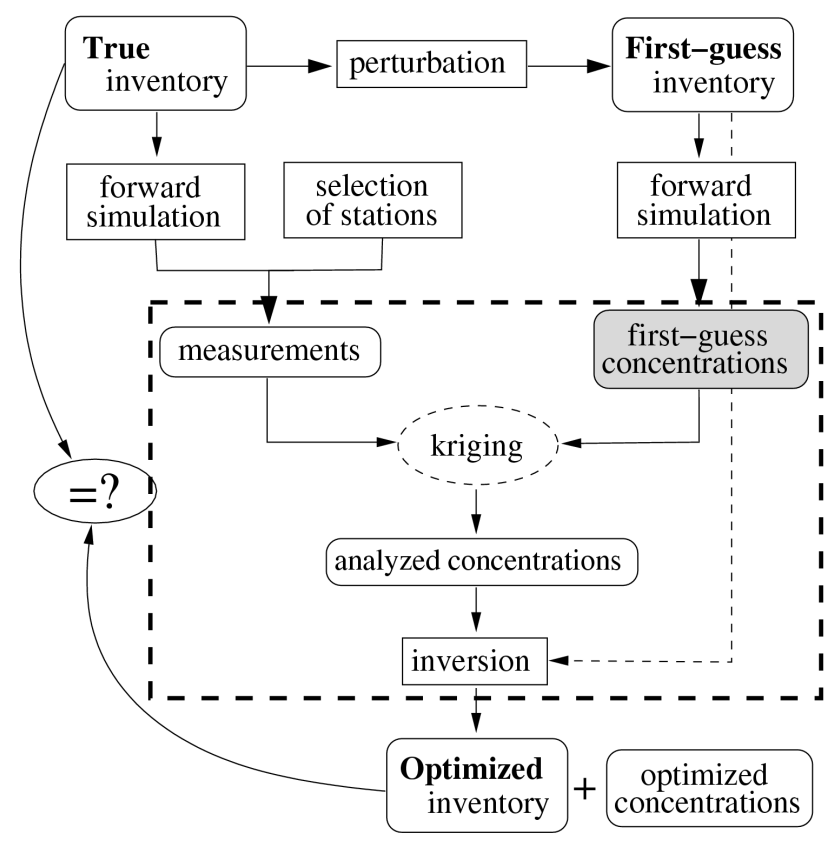

Fig. 1. Principle of the evaluation of the inverse modeling methodology with synthetic cases. The bold-dashed area contains the steps of the inverse modeling methodology itself, which would be performed in a real-case study.

the boundary layer. The mean value of the 2-meter temperature is prescribed $\left(22^{\circ} \mathrm{C}\right)$; a sinusoidal variation is applied to model a typical diurnal cycle (minimum $13^{\circ} \mathrm{C}$ and maximum $31^{\circ} \mathrm{C}$ values reached at 04:00 and 12:00); a realistic vertical profile is built by applying a linear decrease of $6 \mathrm{~K} . \mathrm{km}^{-1}$ with a temperature inversion of $2 \mathrm{~K}$ at the boundary layer height. The evolution of the boundary layer height, $\bar{h}$, is sinusoidal during the day (with a maximum of $\bar{h}=1700 \mathrm{~m}$ at 15:00) and constant during the night $(\bar{h}=300 \mathrm{~m})$.

\subsection{Emissions}

The emission inventory consists of two sources, displayed as 1 and 2 on Fig. 2, which emit the whole set of 16 emitted model species. The proportion of the fluxes of the species are realistic. The maximum intensity of the fluxes of the main species are $10^{14}$ molec.cm ${ }^{-2} \cdot \mathrm{s}^{-1}$ of $\mathrm{CO}, 10^{13}$ molec. $\mathrm{cm}^{-2} \cdot \mathrm{s}^{-1}$ for $\mathrm{NC}_{4} \mathrm{H}_{10}$ and $\mathrm{NO}, 10^{12}$ molec.cm ${ }^{-2} \cdot \mathrm{s}^{-1}$ for $\mathrm{C}_{2} \mathrm{H}_{4}, \mathrm{C}_{2} \mathrm{H}_{6}$, $\mathrm{C}_{3} \mathrm{H}_{6}, \mathrm{HCHO}, \mathrm{NO}_{2}, \mathrm{OXYL}, \mathrm{SO}_{2}$. For each source, the emissions are constant at $E_{\max }$ between 07:00 and 11:00 and at $E_{\max } / 10$ for the rest of the day. The emitted $\mathrm{NO}_{\mathrm{x}}$ consist of a constant ratio of $90 \%$ of $\mathrm{NO}$ and $10 \%$ of $\mathrm{NO}_{2}$.

The first-guess inventory is an underestimate of the true one by $20 \%$ during the five hours of maximum intensity. The two formal cases discussed here consist of the inversion of $\mathrm{NO}_{x}$ emissions during a six-hour time window from 07:00 
(a) NO concentrations as simulated with the true inventory

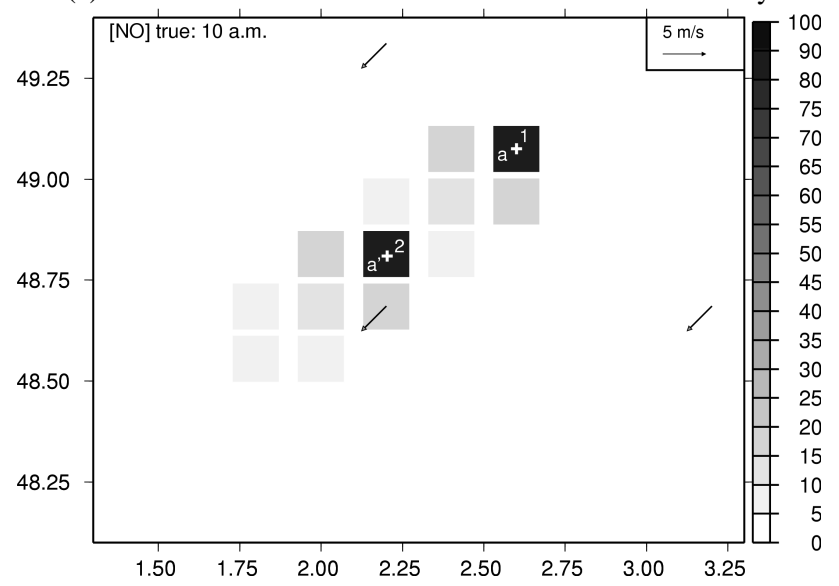

(b) Differences between NO concentrations as simulated with the first-guess and the true inventories

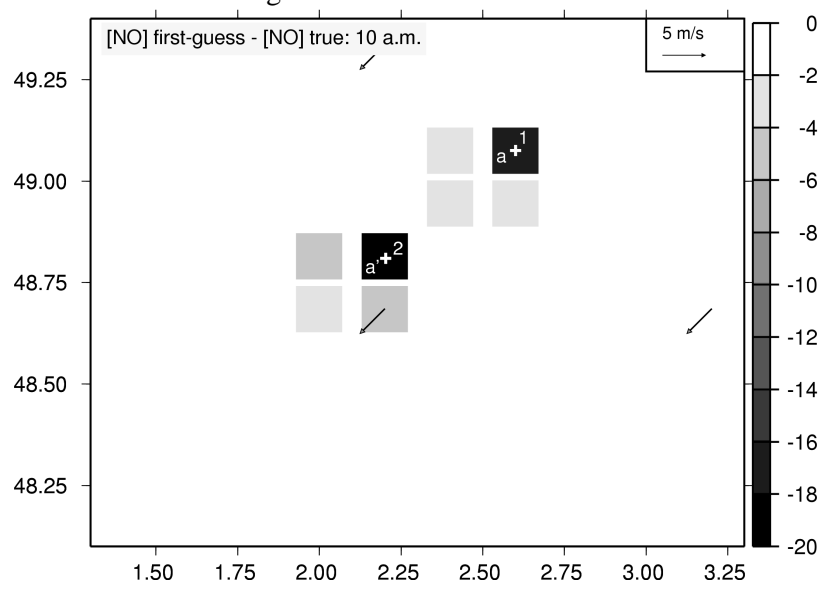

Fig. 2. NO surface concentrations and differences (ppb) for the formal test cases at 10:00 .

to 12:00. The correction coefficient that should be retrieved by the inversion is then 1.25 for the first $5 \mathrm{~h}$ and 1.00 for the last one. The difference between the first-guess and the true inventory leads to differences in simulated $\mathrm{NO}_{\mathrm{x}}$ concentrations, which are indicated on Fig. 2 for NO.

3.3 Formal test case 1: theoretical accuracy of the inverse code

For this first test case, the two measurements stations (a) and $\left(a^{\prime}\right)$ are available (see Fig. 2). These stations deliver "perfect" measurements of NO, i.e. the inversion code must theoretically retrieve the original values. This case is a perfect case for the inversion: all the needed information is provided with no error or uncertainty. Only the errors due to the model may influence the results.

The optimization of the two-term cost function reaches the convergence. The retrieved correction coefficients for both sources are 1.25 for the five perturbed hours of the time win-
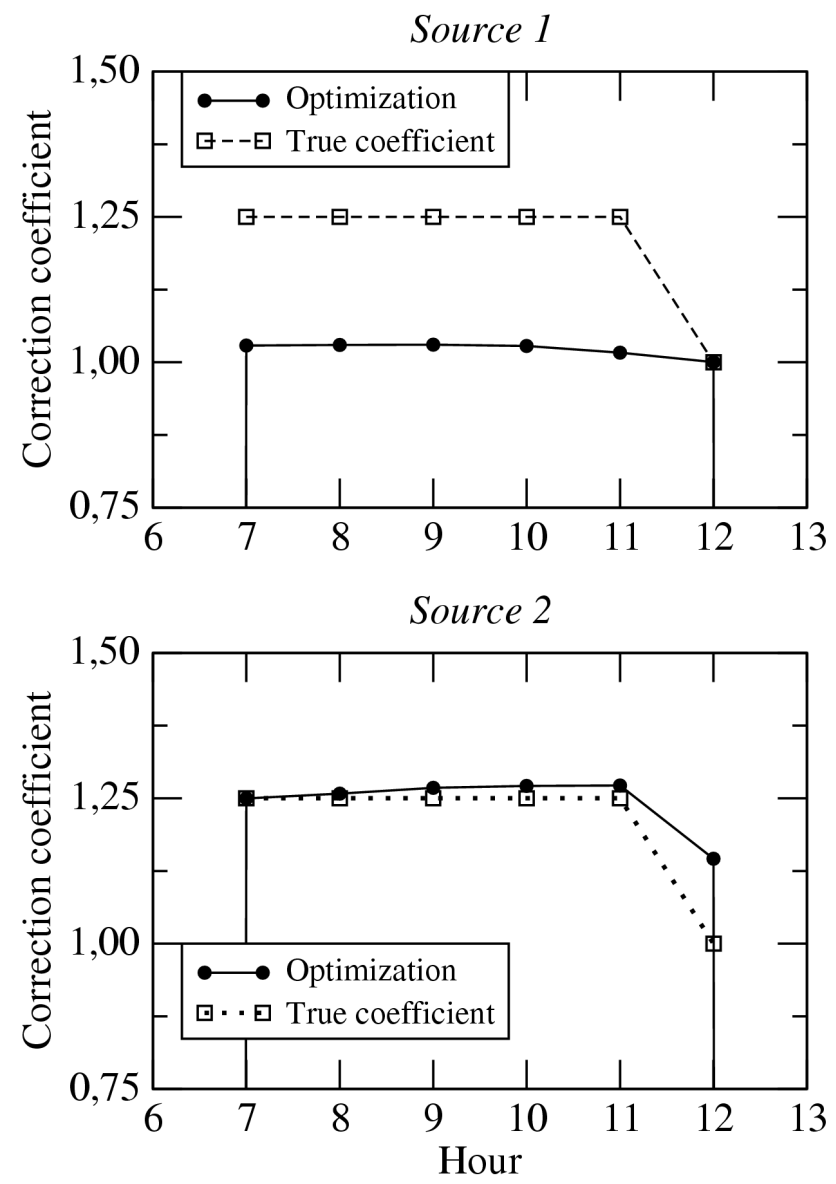

Fig. 3. Correction coefficients for sources 1 and 2 at each hour of the time window for Test Case \#2.

dow and 1.00 for the last unperturbed hour, which is very close to the true emissions. This shows that the accuracy of the inverse model, in an ideal situation, is very high.

\subsection{Formal test case 2: a simple example of a lack of infor- mation}

This second test case is a restricted version of the first one: only the station $\left(a^{\prime}\right)$ delivers perfect measurements. Since the wind direction is constantly northeast, the single information located in $\left(\mathrm{a}^{\prime}\right)$ integrates the effects of both sources.

The optimization of the one-term cost function converges. The results for both sources are displayed in Fig. 3. Source $\# 2$, in which station $\left(\mathrm{a}^{\prime}\right)$ is available, is almost perfectly retrieved by the inversion: the coefficient for perturbed hours varies between 1.25 and 1.27. Nevertheless, it reaches 1.14 for the last unperturbed hour. The intensity of source \#1 is almost not modified by the inversion: the correction for the perturbed hour varies between 1.01 and 1.03 and is 1.0 for the last hour of the time window. 
Although station $\left(a^{\prime}\right)$ is located downwind from source \#1, the influence of this source on the measured concentrations is not very large because of the distance (see map of concentrations on Fig. 2) and because of the very strong effect of source \#2. The information provided by station $\left(a^{\prime}\right)$ is then not relevant to source \#1, which is therefore almost unchanged by the optimization. A slight overestimate of the intensity of source \#2 is nevertheless necessary to obtain the right measured concentrations at station $\left(\mathrm{a}^{\prime}\right)$ by compensating for the underestimation of source \#1. At the last hour, source \#1 is not underestimated anymore but source \#2 remains overestimated because the response in concentrations is shifted in time with respect to the emissions (transport).

The formal test cases have shown that the theoretical accuracy of the inversion code is high. In practice, the quality of the results depends chiefly on the availability of information. The inversion of the second test case underlines two linked effects: (i) first, the over-correction of the source that has the strongest impact on the measurement, whereas the other source is left unmodified; (ii) then the persistence of this over-correction through time because of the time necessary to transport the information from the source to the measurement.

\section{Testing the kriging-constrained methodology on real- istic synthetic cases}

\subsection{Description of the cases}

To test the inverse modeling methodology using kriging constraints, realistic synthetic cases are performed. Contrary to the previous formal test cases, realistic synthetic cases are based on a real pollution event which occurred on 7 August 1998 in the Paris area and is described in detail by Menut (2003). The domain mesh covers a $150 \times 150 \mathrm{~km}$ area with $25 \times 25$ cells over 11 vertical levels. The meteorology used here corresponds to the ECMWF data that were used to forecast the event.

\subsubsection{Emissions}

The emission inventory used in our study has been elaborated by AIRPARIF for the ESQUIF field campaign of the summer of 1998, as described in Vautard et al. (2003). It includes the hourly $6 \times 6 \mathrm{~km}$ fluxes of sixteen anthropogenic emitted species: carbon monoxide, sulfur dioxide, methane, nitrogen oxides, speciated in $10 \%$ of $\mathrm{NO}_{2}$ and $90 \%$ of $\mathrm{NO}$, HONO, and non-methanic VOCs speciated into ten subfamilies according to various studies (Theloke et al., 2000, 2001; Schmitz et al., 2000; Rudd and Marlowe, 1998; Hassel et al., 2000). It constitutes the true inventory that will have to be retrieved by the inversion (see Fig. 1).

The first-guess emission inventory is obtained by perturbing the true inventory, so that $\mathrm{NO}_{\mathrm{x}}$ emissions of the morning traffic peak from 08:00 to 09:00 in the city (displayed on

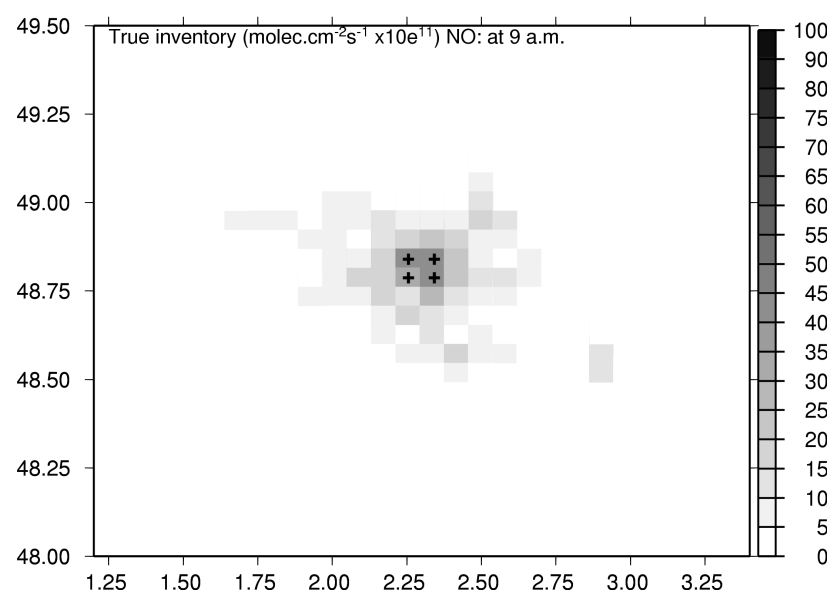

Fig. 4. True emission inventory: NO fluxes at 09:00 on 7 August 1998; $\mathrm{x}=$ perturbed fluxes in the first-guess inventory.

Fig. 4) are over- or underestimated by a given percentage $\epsilon_{E}$, ranging from -70 to $+100 \%$ and representing the emission error to correct. This corresponds to a realistic range for emission inventories: Kühlwein and Friedrich (2000) estimated that the uncertainty may be as high as $35 \%$ for anthropogenic sources and Beekmann and Derognat (2003) and Sillman et al. (2003) proposed a factor of 2 to 3 for biogenic sources.

\subsubsection{Measurements}

The measurement stations are those of the AIRPARIF network. Their locations and characteristics are displayed in Menut et al. (2000b). The true concentrations computed by the simulation run with the true inventory (see Fig. 1) are interpolated at the location of the stations. The measurements of NO or ozone concentrations then generated are obtained by randomly perturbing the true concentrations using a factor $\epsilon_{m}$ which represents the "possible instrumental error". We define ranges from $\epsilon_{m}$ of \pm 0 (perfect measurements) to 10 and $15 \%$. This highest value corresponds to the maximum uncertainty given by AIRPARIF for monitoring instruments. The variances of the measurements (needed for the $\mathbf{R}$ matrix, see Sect. 2.3.3) are computed with the generated measurement value by using real uncertainty functions provided by AIRPARIF.

\subsection{Inversion test cases}

$\mathrm{NO}_{\mathrm{x}}$ emissions in the city from 08:00 to $09: 00$ are to be inverted with hourly measurements available from 09:00 to 17:00 . Several series of inversions are run to test various aspects of the new methodology:

- the quality of the constraints and particularly the interest of the use of our kriging-constrained approach (cases 


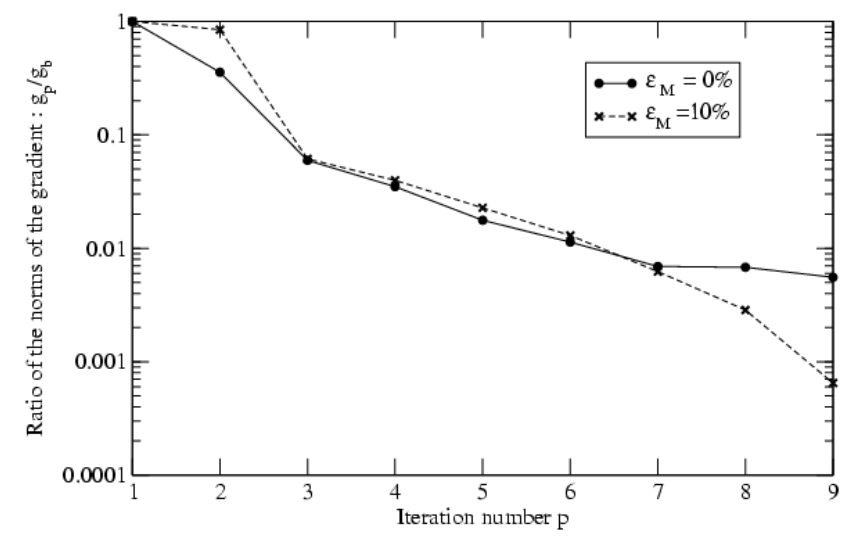

Fig. 5. Evolution of the norm of the gradient through the optimizer's iterations for k-cases using NO constraints with the firstguess inventory $+50 \%$ and $\epsilon_{m}=10 \%$ (converging) or $\epsilon_{m}=0 \%$ (nonconverging).

named k-) compared to the use of measurements alone (cases named $\mathrm{m}$-) or measurements plus a background matrix;

- the quality of the first-guess emission inventory;

- the relevance of the information contained in the constraints: the chemical species used as constraints are either NO or ozone.

To quantify the quality of the results, an indicator for estimating whether the difference between optimized and true emissions is smaller than the difference between first-guess and truth is defined: at one time and one location, the score is given by:

score $_{x}=\left(1-\frac{x_{\text {opt }}-x_{\text {true }}}{x_{f g}-x_{\text {true }}}\right) \times 100$

with $x_{\text {opt }}$, the optimized value of $x, x_{\text {true }}$ the true value and $x_{f g}$ the first-guess value, with $x$ being an emission flux. The value of the score then gives the change in percentage of the difference between first-guess and reality, due to the optimization. A positive score indicates that the difference between simulation and truth is reduced, whereas a negative score indicates that after optimization, the difference between simulation and truth has been increased. A perfect optimization would give a score of $100 \%$, indicating that the difference between first-guess and truth has been reduced to zero by the optimization.

The results for the eight optimized fluxes (four at each of the two hours of the time window) are summarized by computing the average over the eight individual scores. These average scores are listed in Table 1.

A number of cases did not converge, i.e. the maximal number of iterations was reached before the convergence criterion could be matched. For these cases, the decrease in the norm

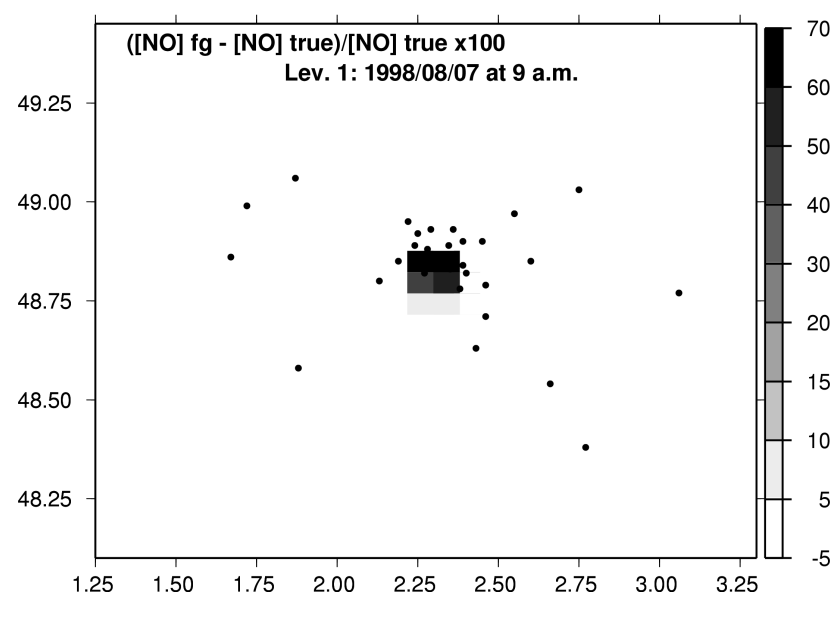

Fig. 6. Differences (ppb) between NO surface concentrations obtained with the true emission inventory and with the first-guess inventory $+100 \%$ at 09:00 .

of the gradient through the iterations performed by the optimizer is not steep enough. The difference between cases that do and do not converge is illustrated in Fig. 5 by the evolution of the norm of the gradient for the k-cases using NO constraints with $\epsilon_{E}=+50 \%$ and $\epsilon_{m}=10 \%$ or $0 \%$. The comparison between the two cases (Fig. 5) shows that for the last three iterations, the norm is decreased by 54 and then $77 \%$ (total decrease of more than 89\%) in the first case and only by 1.6 and then $18 \%$ for the latter (total decrease of less than $20 \%)$.

\subsection{Interest of the new approach}

4.3.1 Maximum use of information in the concentration space

The use of analyzed NO concentrations as constraints to invert $\mathrm{NO}_{\mathrm{x}}$ emissions is a situation in which the measurements may provide maximum information. The influence of an error on $\mathrm{NO}_{\mathrm{x}}$ emissions on $\mathrm{NO}$ concentrations is maximum at the same location and time, and immediately downwind (Fig. 6). The stations are indeed located immediately above and around the emission places (Fig. 6). Nevertheless, the total number of relevant constraints is not sufficient: for the $+100 \%$ inventory which has the largest differences with reality, at 09:00, less than 10 measurements are meaningful, i.e. located where the difference is significant (Fig. 6). Finally, only 6 out of $21 \mathrm{~m}$-cases reach convergence, whereas 19 out of $21 \mathrm{k}$-cases do (Table 1, top half). Moreover, a closer examination of the 6 converging cases show that they all reach the same optimum, which explains that the score is higher when $\epsilon_{E}$ is larger.

When ozone concentrations are used as constraints, the information about $\mathrm{NO}_{\mathrm{x}}$ emissions is more spread out, in space 
Table 1. Average scores of optimizations (in \%) (and matching variances) for $\mathrm{NO}_{x}$ inversion with two types of NO or ozone constraints; $\mathrm{x}=$ convergence not reached.

\begin{tabular}{|c|c|c|c|c|c|c|c|c|c|}
\hline \multirow{2}{*}{$\begin{array}{l}\text { Measured } \\
\text { species }\end{array}$} & \multirow{2}{*}{$\begin{array}{c}\text { Type of } \\
\text { constraints }\end{array}$} & \multirow{2}{*}{$\begin{array}{l}\text { Quality of } \\
\text { meas. } \epsilon_{m}\end{array}$} & \multicolumn{7}{|c|}{ Quality of first-guess emission inventory $\epsilon_{E}$} \\
\hline & & & $-70 \%$ & $-50 \%$ & $-20 \%$ & $+20 \%$ & $+50 \%$ & $+70 \%$ & $+100 \%$ \\
\hline \multirow{6}{*}{ NO } & measure- & 0 & $53.8(10.9)$ & $35.4(21.3)$ & $\mathrm{X}$ & $\mathrm{x}$ & $\mathrm{x}$ & $\mathrm{x}$ & $\mathrm{x}$ \\
\hline & ments & 10 & $49.3(9.9)$ & 29. (19.4) & $\mathrm{x}$ & $-77.4(121.4)$ & $\mathrm{x}$ & $\mathrm{x}$ & $\mathrm{x}$ \\
\hline & alone & 15 & 57. (14.4) & $\mathrm{x}$ & $\mathrm{x}$ & $\mathrm{x}$ & $\mathrm{x}$ & $\mathrm{x}$ & $\mathrm{x}$ \\
\hline & & 0 & $29.8(7.7)$ & $29.1(1.2)$ & 30.3 & 28.8 & $\mathrm{x}$ & $\mathrm{x}$ & 21.9 \\
\hline & kriging & 10 & $31.6(2.7)$ & $31.4(0.5)$ & 32.7 & $26.8(0.7)$ & 25.7 & 25.3 & 21. \\
\hline & & 15 & $29.7(8.7)$ & 30.2 & 42.8 & 17.4 & 26.2 & 22.2 & 20.9 \\
\hline \multirow{6}{*}{ ozone } & measure- & 0 & $\mathrm{x}$ & $\mathrm{x}$ & $\mathrm{x}$ & $\mathrm{x}$ & $\mathrm{x}$ & $\mathrm{x}$ & $\mathrm{x}$ \\
\hline & ments & 10 & $\mathrm{x}$ & $\mathrm{x}$ & $\mathrm{x}$ & $\mathrm{x}$ & $\mathrm{x}$ & $\mathrm{x}$ & $\mathrm{x}$ \\
\hline & alone & 15 & $\mathrm{x}$ & $\mathrm{x}$ & $\mathrm{x}$ & $\mathrm{x}$ & $\mathrm{x}$ & $\mathrm{x}$ & $\mathrm{x}$ \\
\hline & & 0 & $\mathrm{X}$ & 8.3 & 7.3 & 5.7 & 0.6 & $\mathrm{x}$ & $\mathrm{X}$ \\
\hline & kriging & 10 & $\mathrm{x}$ & 10.9 & 13.8 & $\mathrm{x}$ & -4.1 & $\mathrm{x}$ & $\mathrm{x}$ \\
\hline & & 15 & 3.5 & 3.1 & $\mathrm{x}$ & 10.9 & 12.4 & 8.5 & 6.8 \\
\hline
\end{tabular}

and time. An error in $\mathrm{NO}_{\mathrm{x}}$ emissions during the morning traffic peak leads to a incorrect estimation of ozone concentrations at various locations: in the city at the emission time but also in the plume eight hours later (Fig. 7). It should be noted that, since ozone concentrations are the result of various processes, they are not directly linked to emissions. As displayed in Fig. 7, a change of $+100 \%$ in $\mathrm{NO}_{\mathrm{x}}$ emissions leads to variations of less than $15 \%$ in the afternoon ozone concentrations, at an hour of highest sensitivity. The information on the $\mathrm{NO}_{\mathrm{x}}$ emitted during the morning in the city is then principally contained in ozone concentrations in the ozone plume formed in the afternoon. To obtain at least part of these lacking bits of information, kriging is necessary, since very few meaningful measurements are available (Fig. 7). Finally, with ozone constraints, no m-cases reaches convergence, whereas 13 out of $21 \mathrm{k}$-cases do (Table 1, bottom half).

Finally, the use of kriging makes it possible to use part of the information contained in the structure of the first-guess simulation. This additional information, as compared to the information provided by measurements alone, is sufficient to reach a mathematically acceptable solution for the optimization, even when no information is available in the measurements.

\subsubsection{Impact of the new approach}

To assess the impact of the use of kriging as compared to the classical method, cases for which convergence is reached both when using kriging and measurements are studied in particular. For these cases, the variances associated with the average scores (Sect. 4.2) is computed and displayed in Table 1 .

The average difference with true emissions is roughly decreased by 29 to $57 \%$ (and increased for one case) with measurements alone and by 26.8 to $31.6 \%$ with kriging. Nevertheless, the higher variances of the m-cases (9.9 to $121.4 \%$

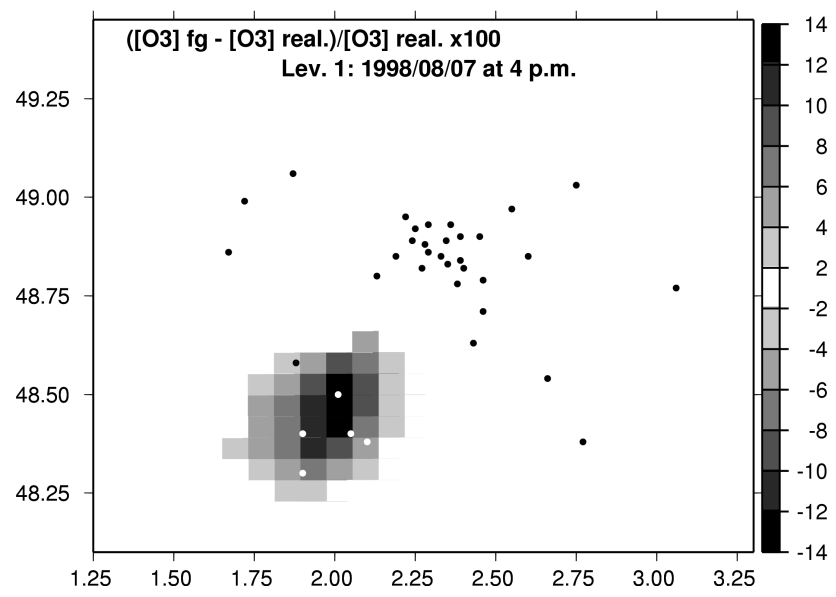

Fig. 7. Differences (ppb) between ozone surface concentrations obtained with the true emission inventory and with the first-guess inventory $+100 \%$ at $16: 00$.

compared to less than $9 \%$ with kriging, see Table 1) indicate that with measurements alone, the corrections of the fluxes are not well distributed, neither in space nor in time.

The m-case in which $\epsilon_{m}=10 \%$ and $\epsilon_{E}=-50 \%$ illustrates the detailed distribution of corrections obtained with three approaches: (i) with measurements alone, (ii) with measurements and a background matrix $\mathbf{B}=$ identity through lack of information, (iii) with the kriging constraints. The differences between the eight optimized and true fluxes are displayed in Table 2. The heterogeneous distribution of the corrections when using measurements alone is shown in the southwest part of the city, for example: the optimized NO flux is only $13.9 \%$ underestimated at 08:00 but more than $37 \%$ overestimated at 09:00. As shown in the middle panel of Table 2, adding the $\mathbf{B}$ matrix leads to a slight homogenization of the space and time distribution of the corrections 
Table 2. Difference in $\%$ between the optimized and the true fluxes for three types of inversion constraints with $\epsilon_{E}=-50 \%$ and $\epsilon_{m}=10 \%$.

\begin{tabular}{lcccc}
\hline Exp. & \multicolumn{2}{c}{$08: 00$} & \multicolumn{2}{c}{$09: 00$} \\
\hline Measurements & -75.7 & -56.3 & -33.4 & -37.2 \\
& -56.3 & -26.6 & -33.1 & +7.4 \\
\hline meas+ [B=1] & -69.3 & -16.6 & -35.2 & 12.4 \\
& -51.4 & -27.7 & -38.3 & -14.6 \\
\hline Kriging & -34.8 & -26.5 & -35.4 & -39.9 \\
& -35.5 & -33.3 & -34.0 & -35.1 \\
\hline
\end{tabular}

compared to the m-case. Finally, when using kriging, the corrections are homogeneously distributed and the first-guess difference of $50 \%$ with the true fluxes is reduced to an average $34.3 \%$.

Too big a change on some fluxes compared to other optimized fluxes may indicate either that the first-guess inventory does not have the same quality everywhere or that the information is not well distributed (see the formal test case 2, Sect. 3.4). In this synthetic case, the difference with the true inventory is the same for all fluxes and the last case is encountered. The interest of using kriging constraints then depends on how the inventory is to be optimized. At a local scale, the first-guess inventory may be assumed to have been established with a reliable layout so that rural and urban cells must retain their relative characteristics. To optimize the inventory as a whole, the corrections should therefore be distributed as homogeneously as possible, which is strongly favored by the use of kriging.

\subsection{Limitations of the new approach}

\subsubsection{Iterative procedure: case of NO constraints}

After the optimization, the average difference between firstguess and true $\mathrm{NO}_{\mathrm{x}}$ emissions is decreased by less than $50 \%$ when using NO kriging constraints (Table 1). Since NO concentrations are directly and almost linearly linked to $\mathrm{NO}_{\mathrm{x}}$ emissions, this reduction may seem not satisfying. The inversion provides not only the optimized emissions but also the matching optimized concentrations (Fig. 1).

The new concentration field could then be used to perform a new kriging analysis in place of the first-guess but still together with the measurements (see Fig. 1). A second inversion, constrained by the new analyzed concentrations, could follow. The results of the optimization could be refined by iterating several kriging-inversion cycles. To test this possibility, two kriging-inversion cycles were run for the k-cases using NO concentrations. When a case had not reached convergence at the first cycle, the second one was performed from the preceding stopping point.

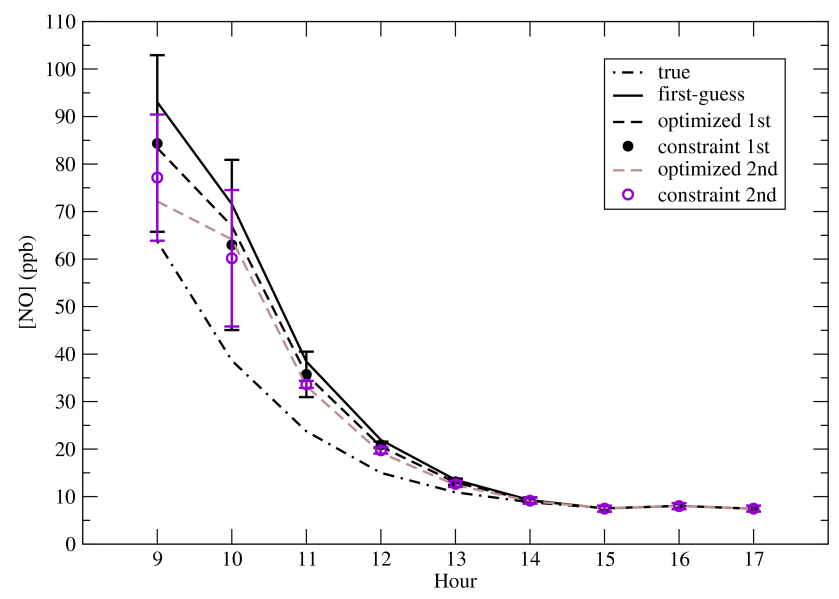

Fig. 8. Times series of NO concentrations for the true inventory, the first-guess $+100 \%$ inventory and the analysis obtained with $\epsilon_{m}=10 \%$ in the southwest part of the city for the first and second optimizations.

Figure 8 illustrates the impact of the cycles on the analyzed and simulated concentrations, with the example of the southwest cell of the four containing optimized fluxes. After the first inversion, the average difference between simulated concentrations (named "optimized 1st") and constraints (named "constraint 1st") is decreased. The inversion is then correctly performed regarding the decrease of the cost function. But because kriging makes use of the first-guess simulation, constraints are shifted toward the first-guess concentrations (Fig. 8) and not as close to the true concentrations as possible. After the second kriging analysis was performed with the same measurements and the first optimized concentrations, the second constraints (named "constraint 2nd") are closer to the truth (Fig. 8). The second optimized concentrations (named "optimized 2nd") are finally closer to the truth than the first optimized.

The average scores after the first and second optimizations are displayed in Fig. 9 for all first-guess and measurements qualities. First, it should be noted that the quality of the measurements has no significant impact: a smaller value of $\epsilon_{m}$ does not systematically lead to a higher score, either after the first or the second optimization (Fig. 9). Moreover, the principle of kriging implies that any additional measurement, whatever its uncertainty, increases the quality of the analysis.

After the second cycle, 19 cases out of 21 reached convergence. For 16 cases, the average scores were increased as compared to the first optimization and range from 46 to $86 \%$ (Fig. 9). For 2 cases $\left(\epsilon_{m}=0 \%\right.$ and $\epsilon_{E}=+50$ and $\left.+70 \%\right)$, the second optimization converges, whereas the first cycle had stopped after too many iterations; moreover, the average scores then reached are higher than $60 \%$ (Fig. 9). The quality of the inventory does not constitute a limitation in the realistic range of -50 to $+100 \%$ : only the cases corresponding to 


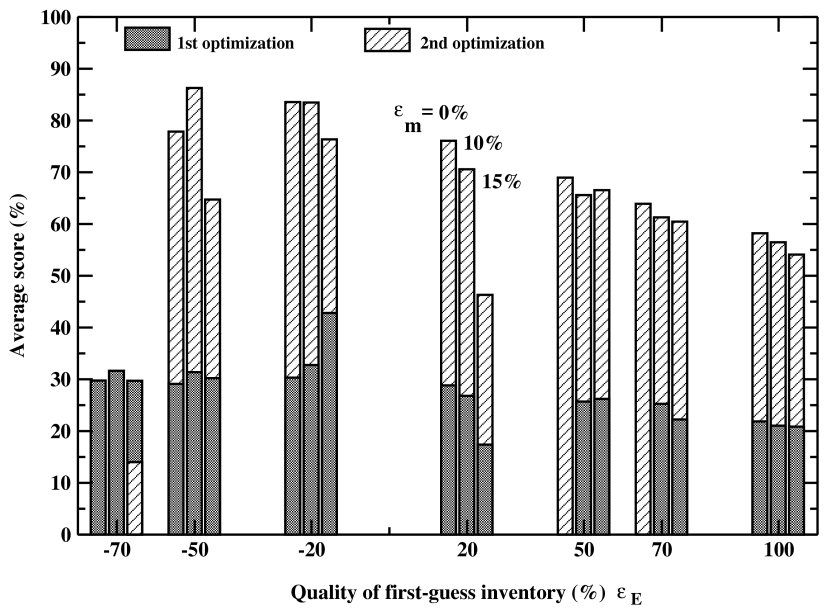

Fig. 9. Average scores (\%) after a first and then a second cycle of kriging-optimization using $\mathrm{NO}$ constraints.

$\epsilon_{E}=-70 \%$ either do not converge at the second optimization or reach a "false" optimum.

\subsubsection{Lack of information: case of ozone constraints}

The average scores of all k-cases using ozone constraints are less than 15\% (Table 1). As explained in Sect. 4.3.1, this is due to the lack of measurements in the ozone plume. This leads the kriging technique to rely heavily on the values computed by the first-guess simulation: the analysis are very close to the first-guess concentrations, as displayed in Fig. 10. Therefore, the optimized emissions are also very close to the first-guess ones. With optimized concentrations almost equal to the first-guess concentrations, the performing of kriging-optimization cycles cannot increase the accuracy of the inversion.

To try and assess the potential impact of additional measurement stations, five virtual stations (not corresponding to any actual AIRPARIF site) were added in the plume. Perfect ozone measurements generated with these stations were added to the ones used for the inversion of the k-cases with $\epsilon_{E}=-70$ to $+100 \%$. The same four cases reached convergence (Table 1). The average scores were increased for $\epsilon_{E}=-50$ and $-20 \%$ (from 8.3 to 11.6 and from 7.3 to 10.9 ) and decreased for $\epsilon_{E}=+20$ and $+50 \%$ (from 5.7 to 4.1 and from 0.6 to -2.3 ). The interest of the additional information thus seems to depend on the quality of the first-guess inventory. The added measurements make it possible to better correct the under-estimation of $\mathrm{NO}_{\mathrm{x}}$ emissions in the morning in the city but the overestimation remained poorly corrected. Note that this rough impact assessment does not constitute a fine network design study.

Finally, this situation shows that the use of kriging constraints cannot compensate for a very important lack of information in the measurements. Actually, no information is

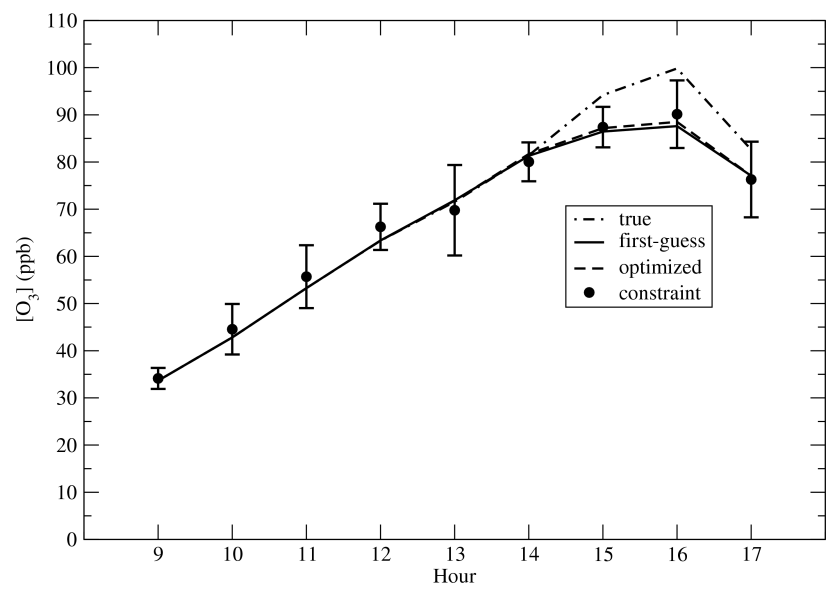

Fig. 10. Times series of ozone concentrations for the true inventory, the first-guess $+100 \%$ inventory and the analysis obtained with $\epsilon_{m}=15 \%$ for a cell located in the plume.

created by kriging. Finally, the use of kriging and even the performing of kriging-optimization cycles increase the accuracy of the inversion only when the information contained in the measurements is relevant enough.

\section{Conclusion}

The main goal of this work is to improve the inversion of emissions at a local scale using a chemistry-transport model. In this paper, we thus presented some hypothesis to use analyzed chemical concentrations provided by a kriging technique. Such a methodology makes it possible to add information on the emission first-guess through the concentration space, thus avoiding the difficulty of adding a priori information in the emission space.

The inverse modeling system is based on the CHIMERE chemistry-transport model and its adjoint (to perform 4-D integration) and the kriging technique used daily for the forecasting of pollution maps in the Paris area.

To evaluate the feasibility and accuracy of this new methodology, synthetic cases of inversion were performed. Three aspects were particularly addressed in our testing: the quality of the constraints, the quality of the first-guess inventory and the relevance of the available information. First, formal cases have shown that the theoretical accuracy of the inversion system is high. Then, the interest and limitations of the new kriging-constrained methodology were tested on realistic synthetic cases based on a real summer pollution event which occurred in the Paris area. It was shown that the information provided by the analyzed concentrations is sufficient to reach a mathematically acceptable solution for the optimization, even when no information is available in the measurements (case of ozone concentrations for which relevant measurements lack in the plume). 
When using NO constraints, for which numerous relevant measurements are available, the use of kriging leads to a more homogeneous distribution of the corrections, both in space and time, as compared to the use of measurements alone or of measurements and a background (identity) matrix. Moreover, it is then possible to double the accuracy of the inversion by performing two kriging-optimization cycles (the second kriging being run with the first optimized concentrations and the measurements). Nevertheless, the case of ozone-constrained inversions show that kriging constraints cannot compensate for a very important lack of information in the measurements.

Two main points have not been addressed in this paper and should be treated in further studies: (i) problems with a longer time period to invert and therefore bigger size, and (ii) the inversion of emissions and key meteorological parameters (such as the boundary layer height) together. The realistic synthetic cases described here only have a size of 8 , whereas a real problem would be at least ten times larger. Even with the use of kriging, it will probably be necessary to decrease the size of the problem before the inversion.

Acknowledgements. The authors thank G. Bergametti (LISA), G. Petron (NCAR) and C. Granier (CNRS), J. F. Meirink and H. Eskes (KNMI) for fruitful discussions about the inversion methodology and the results in this paper. We also thank C. Puel and O. Duclaux as well as the TOTAL company for the financial support and discussions. This work was done under a TOTAL-CNRS grant and in the framework of the PRIMEQUAL2 project OPTEMI supported by the French Ministry of Environment.

Topical Editor F. D'Andrea thanks I. Enting and another referee for their help in evaluating this paper.

\section{References}

Beekmann, M. and Derognat, C.: Monte-Carlo uncertainty analysis of a regional-scale transport chemistry model constrained by measurements from the Atmospheric Pollution Over the Paris Area (ESQUIF) campaign, J. Geophys. Res., 108, 8559, doi:10.1029/2003JD003391, 2003.

Bergamaschi, P., Hein, R., Heinmann, M., and Crutzen, P.: Inverse modeling of the global CO cycle: 1 . Inversion of CO mixing ratio, J. Geophys. Res., 105, 1909-1927, 2000.

Blond, N. and Vautard, R.: Three-dimensional ozone data analyses and their use for short-term ozone prediction, J. Geophys. Res., 109, D17303, doi:10.1029/2004JD004515, 2004.

Blond, N., Bel, L., and Vautard, R.: Three-dimensional ozone data analysis with an air quality model over the Paris area, J. Geophys. Res., 108(D23), 4744, doi:10.1029/2003JD003679, 2003.

Bousquet, P., Ciais, P., Peylin, P., and Monfray, P.: Inverse modeling and annual atmospheric $\mathrm{CO}_{2}$ sources and sinks: 1 . Method and control inversion, J. Geophys. Res., 104, 26 161-26 178, 1999.

Chang, M., Hartley, D., and Chang, W.-L.: Inverse modeling of biogenic isoprene emissions, Geophys. Res. Lett., 23, 21, 30073010, 1996.

Chang, M., Hartley, D., Cardelino, C., Haas-Laursen, D., and Chang, W.: On using inverse methods for resolving emis- sions with large spatial inhomogeneities, J. Geophys. Res., 102, 16023-16036, 1997.

Cirpka, O. and Kitanidis, P.: Sensitivity of temporal moments calculated by the adjoint-state method and joint inversing of head and tracer data, Advances in Water Resources, 24, 89-103, 2001.

Daescu, D., A.Sandu, and Carmichael, G.: Direct and adjoint sensitivity analysis of chemical kinetic systems with KPP: IInumerical validation and applications, Atmospheric Environment, 37, 5097-5114, 2003.

Daley, R.: Atmospheric Data Assimilation, Cambridge University Press, 1996.

Elbern, H. and Schmidt, H.: A four-dimensional variational chemistry data assimilation scheme for Eulerian chemistry transport modeling, J. Geophys. Res., 104, 18 583-18 598, 1999.

Enting, I.: Inverse problems in atmospheric constituent transport, Cambridge University Press, 2002.

Gilbert, J.-C. and Lemaréchal, C.: Some numerical experiments with variable-storage quasi-Newton algorithms, Mathematical Programming, 45, 407-435, 1989.

Gurney, K., Chen, Y.-H., Maki, T., Kawa, S., Andrews, A., and Zhu, Z.: Sensitivity of atmospheric $\mathrm{CO}_{2}$ inversions to seasonal and interannual variations in fossil fuel emissions, J. Geophys. Res., 110, D10308, doi:10.1029/2004JD005373, 2005.

Hartley, D. and Prinn, R.: On the feasibility of determining surface emissions of trace gases using an inverse method in a threedimensional chemical transport model, J. Geophys. Res., 98, 5183-5198, 1993.

Hassel, D., Weber, F., and Schmitz, T.: Zusammensetzung der Kohlenwasserstoffe im Abgas unterschiedlicher Fahrzeugkonzepte, Jülich, Germany, 2000.

Heimann, M. and Kaminski, T.: Inverse modeling approaches to infer surface trace gas fluxes from observed atmospheric mixing ratios, vol. 14 of Approaches to scaling of trace gas fluxes in ecosystems, Elsevier, Amsterdam, 1999.

Hein, R., Crutzen, P. J., and Heimann, M.: An inverse modeling approach to investigate the global atmospheric methane cycle, Global Biogeochemcal Cycles, 43-76, 1997.

Houweling, S., Kaminski, T., Dentener, F., Lelieveld, J., and Heinmann, M.: Inverse modeling of methane sources and sinks using the adjoint of a global transport model, J. Geophys. Res., 104, $26137-26160,1999$.

Kaminski, T. and Heimann, M.: Inverse Modeling of Atmospheric Carbon Dioxide Fluxes, Science 12 October 2001, Vol. 294, no. 5541, 259, doi:10.1126/science.294.5541.259a, 2001.

Kaminski, T., Rayner, P., Heimann, M., and Enting, I.: On aggregation errors in atmospheric transport inversions, J. Geophys. Res., 106(D5), 4703-4716, doi:10.1029/2000JD900581, 2001.

Kasibhatla, P., Heinmann, M., Rayner, P., Mahowald, N., Prinn, R., and Hartley, D.: Inverse methods in global biogeochemical cycles, AGU Press, 324, 2000.

Konovalov, I., Beekmann, M., Richter, A., and Burrows, J.: Inverse modelling of the spatial distribution of $\mathrm{NO}_{\mathrm{x}}$ emissions on a continental scale using satellite data, Atmos. Chem. Phys., 6, 1747-1770, 2005.

Kühlwein, J. and Friedrich, R.: Uncertainties of modelling emissions from road transport, Atmospheric Environment, 34, 46034610, 2000.

Mahowald, N., Prinn, R., and Rasch, P.: Deducing CCl3 F emissions using an inverse method and chemical transport models 
with assimilated winds, J. Geophys. Res., 102, 28 153-28 168, 1997.

Mendoza-Dominguez, A. and Russell, A.: Estimation of emission adjustments from the application of four-dimensional data assimilation to photochemical air quality modeling, Atmospheric Environment, 35, 2879-2894, 2001.

Menut, L.: Adjoint modelling for atmospheric pollution processes sensitivity at regional scale during the ESQUIF IOP2, J. Geophys. Res., 108, 8562, doi:10.1029/2002JD002549, 2003.

Menut, L., Vautard, R., Beekmann, M., and Honoré, C.: Sensitivity of Photochemical Pollution using the Adjoint of a Simplified Chemistry-Transport Model, J. Geophys. Res., 105, 15 37915 402, 2000a.

Menut, L., Vautard, R., Flamant, C., Abonnel, C., Beekmann, M., Chazette, P., Flamant, P., Gombert, D., Guédalia, D., Lefebvre, M., Lossec, B., D., M., Mégie, G., Perros, P., Sicard, M., and Toupance, G.: Measurements and modelling of atmospheric pollution over the Paris area: an overview of the ESQUIF Project, Ann. Geophys., 18, 1467-1481, 2000b.

Mulholland, M. and Seinfeld, J.: Inverse air pollution modelling of urban-scale carbon monoxide emissions, Atmospheric Environment, 29, 497-516, 1995.

Müller, J.-F. and Stavrakou, T.: Inversion of $\mathrm{CO}$ and $\mathrm{NO}_{x}$ emissions using the adjoint of the IMAGES model, Atmos. Chem. Phys., 5, 1157-1186, 2005.

Pétron, G., Granier, C., Khattatov, B., Lamarque, J.-F., Yudin, V., Müller, J.-F., and Gille, J.: Inverse modeling of carbon monoxide surface emissions using Climate Monitoring and Diagnostics Laboratory network observations, J. Geophys. Res., 107(D24), doi:10.1029/2001JD001305, 2002.

Pétron, G., Granier, C., Khattatov, B., Yudin, V., Lamarque, J.-F., Emmons, L., Gille, J., and Edwards, D.: Monthly CO surface sources inventory based on the 2000-2001 MOPITT satellite data , Geophys. Res. Lett., 31, doi:10.1029/2004GL020560, 2004.

Pison, I. and Menut, L.: Quantification of the impact of aircraft traffic emissions on tropospheric ozone over Paris area, Atmospheric Environment, 38, 971-983, 2004.

Quélo, D., Mallet, V., and Sportisse, B.: Inverse modeling of $\mathrm{NO}_{x}$ emissions at regional scale over Northern France. Preliminary investigation of the second-order sensitivity, J. Geophys. Res., 110(D24), D24310, doi:10.1029/2005JD006151, 2005.

Reeves, C. E., Cunnold, D. M., Gerwent, R. G., Dlugokencky, E., Edouard, S., Granier, C., Menard, R., Novelli, P., and Parrish, D.: Determination of emissions from observations of atmospheric compounds, in: Emissions of Atmospheric Trace Compounds, edited by: Granier, C., Artaxo, P., and Reeves, C. E., Kluwer Academic Publishers, 427-476, 2004.

Rödenbeck, C., Houweling, S., Gloor, M., and Heimann, M.: $\mathrm{CO}_{2}$ flux history 1982-2001 inferred from atmospheric data using a global inversion of atmospheric transport, Atmos. Chem. Phys., 3, 1919-1964, 2003.
Rudd, H. and Marlowe, I.: Improvements to the VOC inventory through speciation of white spirits: a report produced for the department of the environment, transport and the regions, Tech. rep., AEA Technology, Oxfrodshire, England, 1998.

Sandu, A., Daescu, D., and Carmichael, G.: Direct and adjoint sensitivity analysis ofchemical kinetic systems with KPP: Part Itheory and software tools, Atmospheric Environment, 37, 50835096, 2003.

Schmidt, H. and Martin, D.: Continental scale adjoint sensitivity of ozone concentrations in the Paris region during the ESQUIF episodes, Journal of Geophysical Research, 108(D17), 8561, doi:10.1029/2001JD001583, 2003.

Schmidt, H., Derognat, C., Vautard, R., and Beekmann, M.: A comparison of simulated and observed ozone mixing ratios for the summer of 1998 in western Europe, Atmospheric Environment, 35, 6277-6297, 2001.

Schmitz, T., Hassel, D., and Weber, F.: Determination of VOC components in the exhaust of gasoline and diesel passenger cars, Atmospheric Environment, 4639-4647, 2000.

Sillman, S., R.Vautard, L.Menut, and D.Kley: $\mathrm{O}_{3}-\mathrm{NO}_{x}-\mathrm{VOC}$ sensitivity indicators in Paris: results from models and ESQUIF measurements, J. Geophys. Res., 108(D17), 8563, doi:10.1029/2002JD001561, 2003.

Talagrand, O.: Assimilation of observations: an introduction, Journal of the Meteorological Society of Japan, 75, 191-209, 1997.

Talagrand, O. and Courtier, P.: Variational assimilation of meteorological observations with the adjoint vorticity equations, Part I - Theory, Quaterly Journal of the Royal Meteorological Society, 113, 1311-1328, 1987.

Theloke, J., Obermeier, A., and Friedrich, R.: Ermittlung des Lösemittelemissionen 1994 in Deutschland und Methoden zur Fortschreibung, im Auftrag des Umweltbundesamtes, Universität Stuttgart, Germany, 2000.

Theloke, J., Obermeier, A., and Friedrich, R.: Abschätzung des Lösemittelemissionen in Deutschland, Gefahrstoffe Reinhaltung Luft, 105-111, 2001.

Vautard, R., Beekmann, M., Roux, J., and Gombert, D.: Validation of a hybrid forecasting system for the ozone concentrations over the Paris area, Atmospheric Environment, 35, 2449-2461, 2001.

Vautard, R., Martin, D., Beekmann, M., Drobinski, P., Friedrich, R., Jaubertie, A., Kley, D., Lattuati, M., Moral, P., Neininger, B., and Theloke, J.: Paris emission inventory diagnostics from ESQUIF airborne measurements and a chemistry transport model, J. Geophys. Res., 108, 8564, doi:10.1029/2002JD002797, 2003.

Wang, Y. and Bentley, S.: Development of a spatially explicit inventory of methane emissions from Australia and its verification using atmospheric concentration data, Atmospheric Environment, 36, 4965-4975, 2002.

Wang, Y., McElroy, M., Wang, T., and Palmer, P.: Asian emissions of $\mathrm{CO}$ and $\mathrm{NO}_{x}$ : Constraints from aircraft and Chinese station data, J. Geophys. Res., D24304, doi:10.1029/2004JD005250, 2004. 